\title{
New information and communication technologies in education system
}

\author{
Zuxra Ismailova ${ }^{1, *}$, and B. Ergashev ${ }^{2}$ \\ ${ }^{1}$ Tashkent Institute of Engineers of Irrigation and Agricultural Mechanization, The Republic of \\ Uzbekistan, Tashkent \\ ${ }^{2}$ Namangan muhandislik technology institute, Namangan, The Republic of Uzbekistan
}

\begin{abstract}
An article in the education system, the use of new information and communication technologies in the process of theoretical and practical issues and is described in more detail on the international experience in this field.
\end{abstract}

\section{Introduction}

As President Shavkat Mirziyoyev noted, "It is increasingly important to accelerate the implementation of projects and projects in the field of information and communication and telecommunication technologies. We must clearly realize that it is difficult to achieve our long-term goals without making radical and positive impacts on the widespread use of modern ICT in all sectors of the economy and in our daily lives. We should, within a short period of time, not only address the existing shortcomings in many types of information services, but also join the ranks of advanced countries with a high level of information and communication technologies" (Mirziyoev SH. 2017).

Modern information and communication technologies in the context of the education system over the past two decades. The issue of improvement and modernization is still relevant. However, the introduction of personal computers, which are now connected to a local, local network and therefore have access to the global (global) Internet because of the low cost of the educational process, has made this work even more rapid (2017).

For successful implementation of the modernization program, which is often based on computer-aided computerization and the Internet, not only educational facilities should be equipped with modern technology, but education organizers and educators must have sufficient knowledge in this area. In fact, there is nothing new about this, but it is necessary to broaden the range of knowledge gained: pedagogical universities have already begun training teachers for this specialty computer classes are being held in schools, and not only administrators, but also administrators of the educational institutions think that it is natural and necessary to have and use personal computers on their desks. But it's not all so simple, and when we look at these things carefully, we see a contradiction - the contradiction between affordable education and its quality.

\footnotetext{
Corresponding author: zukhra.ismailova@mail.ru
} 
The goal of every educator, whether a school or a high school teacher, is to improve the quality of teaching, and the use of information and communication technologies can be very helpful. It is also important for the supervisor to ensure that, in addition to quality, the available technical equipment and other learning resources are available to as many people as possible. That is why one of them is more focused on affordable and quality education.

\section{The main part}

In order to address the emerging problems, special attention should be paid to the training of pedagogical staff. The use of elements of distance learning is important. Distance learning - is a specialized educational services focused on special education for the general population and is based on remote educational information exchange (satellite communication, television, radio, computers, etc.).

Advantages of Distance Education Obviously, distance learning does not solve all the problems of education, but the use of new information technologies can solve a number of problems in higher education:

- Saving costs for tuition;

- Imkoniyati Ability to choose the learning feature itself;

- Yo'q Lack of regional study restrictions;

- Different types of study tools;

- Learn more about new information technologies;

O'rganish Studying of subjects not available in the nearest educational institutions;

Foydalanish Using educational programs and courses from prestigious universities (Ismailova Z.,2019. pp. 63-73).

Distance learning tools- In the distance learning process, traditional and innovative learning tools are based on the use of computer technology and telecommunications, as well as other new information technologies. It is called "software and technical means of education" in the modern language of education. Implemented software and hardware for distance learning should address the following pedagogical tasks:

- Ability to read and pass the computer test;

- Provide a comfortable learning environment;

- Working with students and building relationships through teamwork ( Ismailova Z. et al., 2015. pp. 800-801).

\section{Method and technology}

Reproductive technology. Reproductive technologies are based on a teacher-oriented learning model. The main purpose of technology is to send information. In order to implement reproductive methodology, it is necessary to use teaching materials and teaching materials first. The classic practice of reproductive technology is TV technology. The modern view of this technology is the use of network technologies. In this case, the use of network technologies to deliver teaching materials, and e-mail for teacher-student interaction (Иимухамедов Р. . et al., 2008).

Interactive technologies. Interactive distance learning technologies are based on an individual-centered learning model and are primarily focused on acquiring knowledge and skills. The most striking example of interactive technologies is technology. Modern technologies of interactive technologies are network technologies, as in reproductive technology.It also uses a higher technical form of an individual-oriented model. Computer courses are provided to trainees in the network and learn about their learning situations by 
performing e-mail self-examination tasks and communicating with the teacher by e-mail (2017).

Collaborative Learning Technologies. Collaborative learning technologies are focused on developing reasoning (analysis, synthesis, evaluation), and aim to apply learning to learning groups. These technologies are intended for use in small groups of students. Dialogue network technologies enable the creation of a multifunctional, team-based, virtual learning environment with a variety of interactivity and information transfer.n this virtual environment, the teamwork of students is controlled by the teacher.

Technological platforms. Technological platforms for distance learning mean a set of software and hardware tools that include the management of training procedures and distance learning processes for distance learning services.

TV technology. TV-technology is based on the use of television systems to deliver teaching materials to students and to organize regular teacher-tutor consultations. It is also possible to arrange 'live' sessions using satellite TV and teleports.

Case technology. Case technologies are based on the use of a collection of text, audiovisual and multimedia teaching materials (cases) and providing regular consultations by the tutor for students to learn independently.

Network technologies. Networking technologies are used to provide students with various interactive levels and interactions with teachers and students from telecommunications networks and teaching materials. Network technologies are divided into asynchronous and synchronous types. Technology of distance learning Asynchronous network technologies. Asynchronous technologies are sufficiently diverse, and two of them are popular: Computer-based training (CBT) is an independent learning tool with computeraided learning programs of various levels. That is, independent learning through computer training programs. Web-based training (WBT) is an independent and team-based learning tool for computer-based interactive learning programs. The main differences between WBTs and CBTs are (Ismailova Z.,2019. pp. 63-73):

- Training materials are often stored online (rapid change and prompt delivery);

- Monitoring and managing students' learning activities (administering and controlling computer-based testing);

-Ability to use individual and group communication tools for different levels of interactivity.

Synchronous network technologies. Synchronous networking technologies are a modern distance learning technology that allows participants to stay away from each other in the learning process. Simultaneous technologies are designed to create virtual classes using video conferencing tools and interoperability. Simultaneous technologies require all students in the virtual classroom to participate simultaneously, and even enable effective integration of different models of teaching during one session [6

The distance learning complex is much more comfortable. But why is distance learning needed? It is natural to ask. The answer to this question can be summarized as follows:

-Yangi New opportunities for learning (low cost of education, time and place, etc.)

- Cheklangan Limited number of students enrolled in educational institutions

- Increasing the number of people wishing to study

- Paydo The emergence and development of high-quality information technology

- Increasing international integration. The above-mentioned conditions and possibilities show the need for distance learning

Based on the foregoing, we provide descriptions and definitions of some of the terms that are currently being repeated throughout the educational process. There are different models and forms of distance learning in the education system, which are subject to the following conditions:

- geographical conditions (eg, country territory, remote location, climate); 
- general level of information and computerization of the country;

- level of communication and development of vehicles;

- the degree of application of information and communication technologies in the learning process;

- traditions used in education;

- availability and potential of scientific and pedagogical staff for the system of distance learning, etc.

In modern conditions, the most effective way to increase the effectiveness of the education is the creation of interactive teaching methods. What are the interactive methods? How do they have didactic potential? What are the benefits that effectively used interactive methods

in the learning process? Here's a brief answer to these questions. The concept of "Interactive" is expressed in English language as "interact" ("interact"), meaning "inter" and "act" from the linguistic point of view.

Interactive learning is a learning based on the organization of students' interaction in the pursuit of knowledge, skills, qualifications and the development of specific ethical qualities.

Interphase students have knowledge, skills, competence and specific ethics have the capacity to work together on the basis of mutual co-operation in the pursuit of quality assurance. From a logical point of view, interactions represent, first and foremost, the social aspects of dialogue, dialogue and interaction.

From a logical point of view, interactions represent, first and foremost, the interaction of social actors with dialogue, interaction based on activities.

Everyone in the field of education is well aware that traditional education is based on dialogue and is organized in the following relationships (in Figure 1):

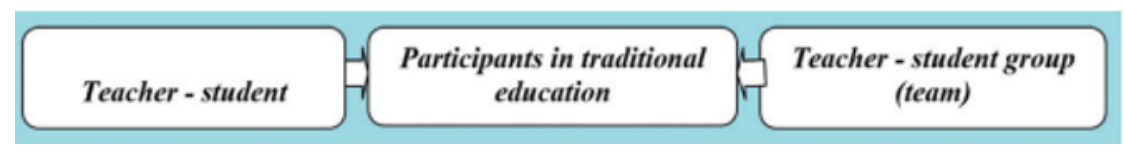

Fig.1. Conversation in traditional education.

The interactive TT is based on the key stakeholders in the learning process - the cooperation between teachers, student and student groups, the opportunity to exchange views, to have free thinking, to express their personal opinion, to seek solutions in problem situations, the student-student group, respect, mutual understanding and support of each other, the sincere unosabatda be described, such as a spirit of unity.

Interviewing is facilitated by the following individuals:

Technology in education is commonly defined as a technical device or tool used to enhance instruction. According to Lever-Duffy, McDonald, and Mizell (2005).

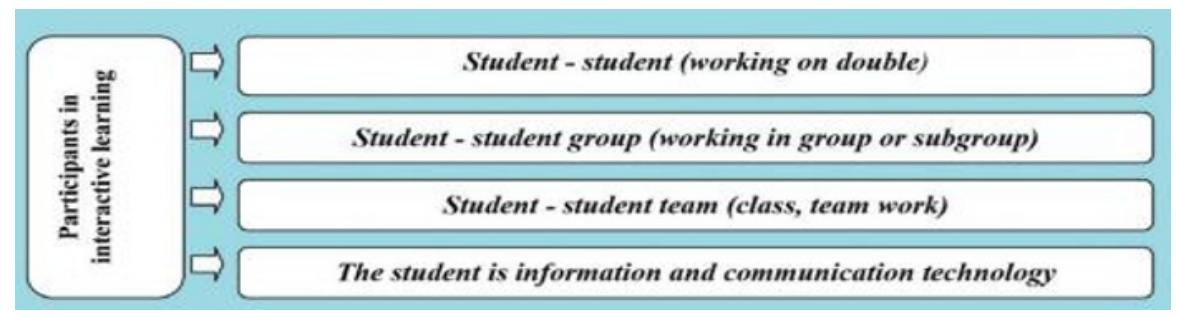

Fig.2. Interview with Interactive TT (Dialogue). 
"Educational technology might include media, models, projected and non-projected visual, as well as audio, video and digital media." These authors claim that some "educators may take a narrower view" and are likely to "confine educational technology primarily to computers, computer peripherals and related software used for teaching and learning" (Lever-Duffy. et al., 2005, pp. 4, 5). This definition does not take into consideration the pedagogical principles upon which the applications of various technologies into educational inquiry are based. Such a definition is narrow because it isolates technology from pedagogical processes that it is intended to support. It does not connect instructional technology with the learning objectives, methods of instruction, learning style and pace of learning, assessment and evaluation strategies, including follow-up procedures. Specifically, technology integration should incorporate the technological skill and ability to use pedagogical knowledge as a base for integrating technology into teaching and learning. This implies that teachers should develop strategies to motivate students to keep them focused as the instruction progresses and to consider that different students prefer different learning styles and that they learn at different rates.

It is important that teachers use a variety of teaching methods, and students must be taught to use the newly acquired knowledge and skill as well as to critically evaluate and modify such knowledge. In other words, teachers should be able to engage students in an exploratory learning experience which is designed to stimulate thinking (Duranov M. et al., 2002. p. 276) the essence of teaching and learning is to help learners acquire knowledge and use the knowledge they have acquired to create other knowledge. Duranov $\mathrm{M}$ eloquently states: "To instruct someone ... is not a matter of getting him to commit results to mind. Rather, it is to teach him to participate in the process that makes possible the establishment of knowledge. We teach a subject not to produce little living libraries on that subject, but rather to get a student to think mathematically for himself, to consider matters as an historian does, to tak e part in the process of knowledge-getting. Knowing is a process not a product." This can imply that teaching software skills without consideration to the basic foundation knowledge that justifies their application is likely to result in rote memorization of disjointed information on various technologies used. Ausubel (Ausubel D. et al., 1978) claims that this type of teaching method is likely to lead to forgetfulness.

In a broad sense, technology integration can be described as a process of using existing tools, equipment and materials, including the use of electronic media, for the purpose of enhancing learning. It involves managing and coordinating available instructional aids and resources in order to facilitate learning. It also involves the selection of suitable technology based on the learning needs of students as well as the ability of teachers to adapt such technology to fit specific learning activities. It calls for teachers' ability to select suitable technology while planning instruction. It also requires teachers to use appropriate technology to present and evaluate instruction as well as use relevant technology for follow-up learning activities. Such a broad definition of technology in education will help teachers develop arational approach toward technology integration.

Problems of Technology Integration. Human technology, which is a component of the Technical Knowledge Objective, relates to labor, technological processes, materials, and human experience. The diagnostics of vocational training teachers are defined as the technical component of integration in the process of teaching and the content of the engineering component, which is the subject of diagnostics and training, of the teacher. Thus, the integration of pedagogical and technical knowledge is largely achieved through special methods of teaching various technical subjects. The relationship between methodology and non-pedagogical sciences to different components is not the same. The most current issues are the content of teaching in this subject. One of the peculiarities of this activity is the integration of 
pedagogical and technical knowledge, taking into account the essence and content of the teacher's professional activity.

The study of Leh ( Leh, A. 2005. pp. 25-41) reveals that teachers admitted "they did not resist technology per se but agreed that they could not fully integrate it into their own practices because of the organizational, administrative, pedagogical, or personal constraints"( Leh, A. 2005. p. 19). Leh claims that the teachers acknowledge, "technology was more of a problem with multiple facets rather than a solution...". Defining instructional technology in broad spectrum helps educators, especially inexperienced teachers, understand the pedagogical issues to be considered when using technology to enhance the process of teaching and learning. Leh also calls for the "the national organizations involved in teacher standards to recognize that teachers need to ... develop a foundation upon which to build their understanding of technology integration (Leh A.2005.p.46). Technology should not be treated as a separate entity but should be considered as an integral part of instructional delivery.

\section{Discussion}

The primary model. In this form of distance learning, there is no need for direct training in the daytime department, and all training is organized at some distance. However, students are in constant contact with teachers attached to it. Local representatives will be set up to advise students and take the final exam. At the same time, the forms and methods of the educational process are freely chosen by the student and the student. Most open universities are based on a standard model of teaching, such as this model of distance learning at the UK Open University.

Secondary model.Training at the educational institution is conducted both in full-time and part-time and part-time distance education. Both schedules and training programs are the same. for students, control is assessed using the same criteria.This dual model of distance learning used in an educational institution is not always useful, as most of the training is covered by students. For example, a dual model has been used in Australian universities (Anderson, C. L. \& Borthwick, 2002. p.14).

Mixed model. This model covers various forms of distance learning, or rather integration of different issues, for example, students receive a part of the course material in parallel with distance learning, while the other directs it in parallel. Some sessions are conducted in the form of virtual seminars, presentations, lectures. The more information and communication technologies provided by an educational institution, the more diverse the forms of education can be. These integrated forms of teaching are being used at Massey and New Zealand universities Consortium.

This model is based on the interaction of two educational institutions, which is based on the interdisciplinary function of the production of learning materials and their distance learning. While the first institution is engaged in the development of teaching materials for distance learning, the second institution provides the implementation of virtual learning groups teaching tools or distance learning programs. In interaction, these working institutions may be universities, or educational centers faculties and even business and government organizations.

This model of teaching has been used, for example, by the Open Education Agency in Canada Franchising. In this model, based on the franchisee of distance learning, communication institutions exchange distance courses that they have created. A distinctive feature of this model is that a student who intends to study in a particular institution will have the opportunity to obtain a diploma of the same size but with a high quality of education, through a consortium of mature institutions. Educational institutions based on 
the franchise model may include Open University - Business Higher Education and Eastern European Universities. Validation. This model of distance learning is a common form of teaching. All educational institutions that communicate with each other conclude an agreement on equal distance learning. Together they create a distance learning program and course, and diplomas and certificates are equally recognized (Leh A.2005.p.46).

\section{Conclucions}

Summarizing the above, we can say that the introduction of distance learning in educational institutions is of great benefit. The system of higher education has all the conditions for its implementation.

All higher education institutions of the country are equipped with computers, information and communication technologies. They are all connected to the Internet.

The widespread introduction of these technologies in the education system will help to solve many problems faced by universities in a timely manner (Ismailova Z. et al. 2019.pp. 734-751).

The introduction of modern information and communication technologies into the learning environment has contributed to the creation of a new form of learning - distance learning, in addition to traditional teaching methods.

In distance learning, students and teachers interact with each other through spatial interdisciplinary training courses, forms of control, electronic communication and other Internet technologies.

Distance learning based on the use of Internet technology provides access to the global information education network, and performs a number of new functions with the principle of integration and interaction.

\section{References}

1. Sh.M. Mirziyoev, Resolution "On measures to radically improve the conditions for the radical development of information technology in the Republic of.Uzbekiston."

2. A.T. Kejabaev, Prospects for the development of ICIT in the economy of Uzbekistan. Monograph, p. 78, Palmarium academic publishing (Germany, 2015)

3. Int. Elect. J. of Int. Fin. and Acc. No. 4 (2017) www.interfinance.uz

4. R. Ishmuhamedov, A. Abdukadirov, A. Pardaev, Innovative technologies in education (practical recommendations for teachers of educational institutions). Istedod foundation (2008)

5. Z.H. Yuldashev, D.N. Ashurova, The use of innovative and information technologies in the education system is a requirement of the time. Public Education, No 1 (2006)

6. Z. Ismoilova, Pedagogika. Tashkent. Molia, p.153 (2010)

7. Z.K. Ismailova, S.N. Utkina, D.O.Ximmataliev, The problem of integrating technology into teaching and learning process. J. Sust. Agric., Tashkent (2019)

8. Z.K. Ismailova, B. R.Mukimov, Directions of psychologization of higher professional pedagogical education». J. Eur. of Res. and Refl. in Ed. Scie. №7(8), pp. 58-63 (2019)

9. Z.K. Ismailova, D. Mustafoeva, Competence of the manager on improving the efficiency of the educational process. J. Eur. of Res. and Refl. in Ed. Scie. №7(8), pp. 63-73 (2019) 
10. Z. K. Ismailova at al., The role of the rules of design and planning of teaching technology at lectures in the preparation of future professional teachers. Ped.: trad. and innov., pp. 218-220 (2015)

11. Z. K. Ismailova, Sh. A. Raupova, A. Jumanov, Information-psychological violence as a factor of social manipulation. Young scientist, No. 8, pp. 800-801(2015)

12. Z. K. Ismailova, D. O. Himmataliev, M. Kh. Baibaeva, Main issues of integration of education and production and ways to solve them. Ped.: trad. and innov., pp. 216-218 (2015)

13. Z.K. Ismailova, M. Kh. Baybaeva, B.R. Mukimov, General patterns and principles of education. Young Scientist, No. 8, 934-937 (2015)

14. Z. Ismailova et al., The role of modern women in society and family. Opción, 35, Especial No.21, pp. 734-751(2019)

15. J. Lever-Duffy, J.B. McDonald \& Al.P. Mizell, Teaching and learning with technology. San Francisco: Pearson (2005)

16. M.E. Duranov, Professional and pedagogical activity and research approach to it. Monograph. Chelyabinsk: ChGAKI, p. 276 (2002)

17. D.P. Ausubel, Educational psychology: A cognitive view. (2nd ed.). New York, Holt, Rinehart \& Winston (1978)

18. A.S. Leh, Learned from service learning and reverse mentoring in faculty development: A case study in technology training. J. of Tech. and Teacher Ed., 13(1), pp. 25-41 (2005)

19. C.L. Anderson, \& A. Borthwick, Results of separate and integrated technology instruction in pre-service training. ERIC Reproduction Document. IR021919, p.14 (2002) 